funded by NIH grants P50AG16574, P50NS72187, and R01AG37491.

Reply from the Authors: We thank Drs. Freeman et al. and Fernández-Torre for their comments.

Freeman et al. report 2 additional cases of sCJD mimicking NCSE with the same misleading EEG presentation, which confirms our findings. ${ }^{1}$ In particular, EEG responses to external stimuli and attenuation with drowsiness indicate that an epileptic origin can be excluded. We were pleased that Freeman et al. agreed with our conclusion that ${ } \mathrm{CJD}$ should be considered as a differential diagnosisrather than as a cause-of apparent refractory NCSE.

We reviewed the literature (supplemental table e-2) including the case reported by Fernández-Torre et al. ${ }^{2}$ In their report, the authors vacillated between a diagnosis of genuine NCSE or nonepileptic activity related to $\mathrm{sCJD}$. Based on our series ${ }^{1}$ and other case reports, ${ }^{9}$ we suggest that the patient reported by Fernández-Torre et al. did not show NCSE.

Dr. Fernández-Torre agreed that recognition of a periodic EEG activity precludes an epileptic origin, but questioned the EEG activities occurring early in the course of sCJD. This pseudorhythmic pattern may be due to the short duration and initial background activity between the periodic sharp waves.

In addition, the EEG showed no organization in frequency, which precludes an ictal discharge. EEG responses to stimulation may help to discriminate between epileptic and nonepileptic activities. Our patients had only mild impairment in their level of consciousness, without impairment of the level of vigilance.

Even in patients with an altered mental status, subtle clinical improvements can be detected when the EEG activity of NSCE is corrected by an AED. ${ }^{7}$
We agree that early identification of patients is difficult and strict criteria should be used to avoid an overdiagnosis of NCSE in patients with nonepileptic encephalopathies. Testing should include repeated EEGs and clinical parameters to gauge reaction to drugs and endogenous/exogenous stimuli.

Bertrand Lapergue, Vincent Navarro, Paris, France

Disclosure: See original article for full disclosure list.

Copyright (C) 2011 by AAN Enterprises, Inc.

1. Lapergue B, Demeret S, Denys V, et al. Sporadic Creutzfeldt-Jakob disease mimicking nonconvulsive status epilepticus. Neurology 2010;74:1995-1999.

2. Fernandez-Torre JL, Solar DM, Astudillo A, Cereceda R, Acebes A, Calatayud MT. Creutzfeldt-Jakob disease and nonconvulsive status epilepticus: a clinical and electroencephalographic follow-up study. Clin Neurophysiol 2004; 115:316-319.

3. Cohen D, Kutluay E, Edwards J, Peltier A, Beydoun A. Sporadic Creutzfeldt-Jakob disease presenting with nonconvulsive status epilepticus. Epilepsy Behav 2004;5:792796.

4. Rees JH, Smith SJ, Kullmann DM, Hirsch NP, Howard RS. Creutzfeldt- Jakob disease presenting as complex partial status epilepticus: a report of two cases. J Neurol Neurosurg Psychiatry 1999;66:406-407.

5. Fernandez-Torre JL. Nonconvulsive status epilepticus in Creutzfeldt-Jakob disease. Clin Neurophysiol 2006;117: $1879-1880$

6. Parchi P, Giese A, Capellari S, et al. Classification of spontaneous Creutzfeldt-Jacob disease based on molecular and phenotypic analysis of 300 subjects. Ann Neurol 2004;56: 702-708.

7. Kaplan PW. EEG criteria for nonconvulsive status epilepticus. Epilepsia 2007;48(suppl 8):39-41.

8. Jirsch J, Hirsch LJ. Nonconvulsive seizures: developing a rational approach to the diagnosis and management in the critically ill population. Clin Neurophysiol 2007;118: $1660-1670$

9. Wieser HG, Schindler K, Zumsteg D. EEG in Creutzfeldt-Jakob disease. Clin Neurophysiol 2006;117: 935-951.

\title{
CORRECTION
}

\section{Postpuncture CSF leakage: A potential pitfall of radionuclide cisternography}

In the article "Postpuncture CSF leakage: A potential pitfall of radionuclide cisternography" by K. Sakurai et al. (Neurology $\left.{ }^{\circledR} 2010 ; 75: 1730-1734\right)$, there is a mistake related to the "opening pressure" in table 1 . The values of opening pressure in table 1 , column 7 , were based on $\mathrm{mm} \mathrm{H}_{2} \mathrm{O}$, not $\mathrm{mm} \mathrm{Hg}$. The column heading should have read "Opening pressure, $\mathrm{mm} \mathrm{H}_{2} \mathrm{O}$." The authors regret the error. 


\section{Neurology}

\section{Postpuncture CSF leakage: A potential pitfall of radionuclide cisternography Neurology 2011;76;1112 \\ DOI 10.1212/WNL.0b013e318217e733}

\section{This information is current as of March 21, 2011}

Updated Information \&

Services

Permissions \& Licensing

Reprints including high resolution figures, can be found at: http://n.neurology.org/content/76/12/1112.full

Information about reproducing this article in parts (figures,tables) or in its entirety can be found online at:

http://www.neurology.org/about/about_the_journal\#permissions

Information about ordering reprints can be found online:

http://n.neurology.org/subscribers/advertise

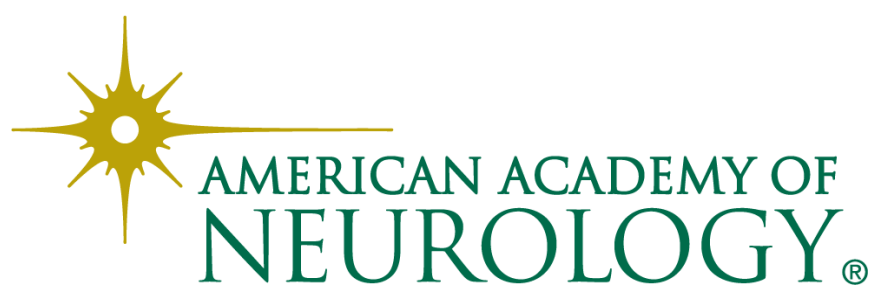

